\title{
Parenting Styles, Sex Education Locality and Self-Efficacy as Predictors of Teenagers' Experiment with Sex
}

\author{
Mokuolu Bolade Olubunmi $^{1}$, Ilori Stephen Oluyemi ${ }^{1} \&$ Ajiboye Adedotun Samuel ${ }^{2}$ \\ ${ }^{1}$ Department of Psychology and Behavioural Studies, Ekiti State University, Ado-Ekiti, Nigeria \\ ${ }^{2}$ Departmental of Psychiatry, Ekiti State University Teaching Hospital, Ado Ekiti, Nigeria \\ Correspondence: Mokuolu Bolade Olubunmi, Department of Psychology and Behavioural Studies, Ekiti State \\ University, Ado-Ekiti, Nigeria
}

Received: February 15, 2019

Accepted: May 15, 2019

Online Published: May 20, 2019

doi:10.5539/ijps.v11n2p80

URL: https://doi.org/10.5539/ijps.v11n2p80

\begin{abstract}
The issue of sexuality among teenagers was investigated in this study to assess factors that could predispose them to it. Factors such as parenting style, sex education, locality and self-efficacy were assessed to know the extent of their influence on teenagers' experiment with sex. Three hundred and Sixty four students (220 males, 67 Females In Agege and Ipaja Local government, Lagos State and 44 males, 33 Females in Esure, Ekiti State) participated in the study. Result showed that permissive and authoritarian parenting styles influence teenagers' experiment with sex, while authoritative parenting does not. Also sex education and self-efficacy significantly predict sex experimentation. There is also relationship between experimenting with sex and self-efficacy, permissive parenting, authoritarian parenting and sex education, but not significantly related to authoritative parenting. The study found a significant main effect of sex and locality on experimenting with sex, while teenagers in rural setting are significantly higher in experimenting with sex and authoritarian parenting than their counterparts in urban setting, those in urban setting are significantly higher in self-efficacy, authoritative parenting and comprehensive sex education.
\end{abstract}

Keywords: parenting style, sex education, self-efficacy, teenagers’ experiment, sex

\section{Introduction}

\subsection{Background to the Study}

A teenager is a young person whose age falls within the range of thirteen years to nineteen years (13-19years). They are called teenagers because their number ends with 'teen'. Most societies traditionally had formal ceremony to mark changes from childhood to adulthood. This stage is called the adolescence stage, whereby major changes occur at varying rates in physical characteristics, sexual characteristics, and sexual interests, resulting in significant effects on body image, self-concept, and self-esteem. They increase their peer focus and involvement in peer related activities, place greater emphasis on social acceptance, and seek more independence and autonomy from parents (APA, 2015) Adolescence period has always been turbulence if not well managed. During this period, teenagers get themselves involved in violent acts, delinquent behaviours, alcoholism, substance use and abuse, sexual activities that may result into experimentation with sex.

According to Collins, Welsh, and Furman (2009), dating plays a part in adolescent's healthy development. But when teens are dating exclusively (going steady), they are more likely to have sex earlier. Adolescents who have sex earlier are not likely to use contraception, putting them at greater risk of pregnancy and sexually transmitted diseases (STDs).

In other words, experimentation with sex can be referred to as the ways in which individuals try out sexual intercourse or any form of sexual activities. Collins, Welsh and Furman (2009) in their research posited that thirty nine per cent of boys who have had sex may have had one partner. The likelihood of sex increases with each school grade level from 32 percent to 62 percent between 2006 and 2008. Also Singh and Cuca (2000) argued that most teens tend to get involved in sexual activities in order to know how it feels being involved in such situations, they probably want to try it out and see what level of satisfaction that could be derived. This may be as a result of influence from peers, society, parents, orientation e.t.c. 
Research by Saltzman (2011) showed that most children have had sexual contact with other children at times during childhood and this is expected part of child development. In keeping their judgemental and largely negative understanding of human sexuality, religious fundamentalists, hypocrites, and other purveyors of morality often try to demonize any kind of sexuality other than straight intercourse between legally married partners. These sex hating, sex fearing types frequently attempt to portray childhood sexuality as something wicked, claiming that a child's interest in sex and child's experimenting sexually with others is somehow perverse or abnormal but this may be simply mistaken. Saltzman (2011) posited that there is no age limit about when sex should come up because curiosity about sex and sex experimentation at any age are normal features of normal human life. He argued that this does not mean that sexual acting between children, and particularly between siblings should be condoned, allowed or encouraged, but only that most instances of it would be best seen and understood as a kind of development play, very different indeed from adult sexuality.

Carole and Carlo (2002) believed that parents are the strongest influence of their children's personality, actions, moral behaviours and emotional problems. Basically, parents are known to be the major source of socialization. That is, basic development of individual is being influenced through parents. There are many ideals about how to rear children. Some parents adopt their own parent's style; some read books about parenting and some others get advice from friends. Parenting style is a psychological construct representing standard strategies that parents use in their child rearing. According to Moore \& Pelper (1998), the most common method used by parents to enforce moral standards is power assertion which includes threat, physical punishment, depriving the child of privileges and generally taking advantages of being bigger, stronger, and more powerful. Okorodudu (2003) listed environmental factors, social factors, physical factors, psychological factors, peer influence, drug abuse and family factors as cause of anti-social behaviour which may likely lead them to sex experimentation. Eke believes that the biological or genetic makeup of individuals can predispose adolescents' engagement in delinquent activities. Chromosomal abnormalities among them may predispose them to anti-social behaviour.

Parenting styles are categorised into three major forms; the authoritative, the authoritarian, and the permissive parenting styles (Baumrind 1991). Ang \& Groh (2006) stated that authoritarian parenting constitutes parents who are often strict, harsh, and high in parent -child communication but low in child - parent communication. Children from most Caucasian authoritarian families have been found to exhibit poor social skills, low level of self-esteem, and high level of depression. Therefore, there may be high tendency that children from this parenting style tend to engage in sexual activities from someone that show emotion and give comfort to them. Authoritative parenting according to Ang \& Groh (2006) is flexible and responsive to the child's needs but still enforce reasonable standard of conduct. The parents in this category are high on warmth, moderate on discipline, high in communication and moderate in expectation. Permissive parenting styles are those who do not imposes fear, restriction, rules or limit on their children, those parents are high on warmth, very low on discipline, low in parent to child communication but high in child to parent communication.

Several researches have shown that adolescents from permissive parenting are more prone to delinquent behaviour and health problems. However, if teenagers from permissive parenting style were allowed to do whatever they like and get whatever they need at their own convenient time, there may be high possibilities of engaging more in sex experimentation than other teenagers from other parenting style

Also, the orientation received from the society, parents and various institutions around may largely influence behaviours that are put up or expressed by individuals. Education on how different behaviours should be managed in the society is very important. This includes gaining of information about sex and sexuality, to negotiate sexual relationships safely and responsibly. Sex education involves a comprehensive course of action by the school, calculated to bring about the socially desirable attitudes, practises and personal conduct on the part of the children and adults, that will best protect the individual as a human and the family as a social institution (Keenan 2010)

The form of education an individual receives about sex may probably influence such individual's experiment with sex. There are high tendencies that a teenager who receives low sex education would be involved in sex experimentation. This could be as a result of their little or no sex education. In other words a teenager who receives high education may likely be low in experimentation with sex and may have a high sense of self-efficacy as regarding his/her attitude toward sex experimentation. Therefore, such teenagers may be able to say Yes or No as situations demand. A teenager who receives comprehensive sex education is expected to have a strong self-efficacy than teenager who receives low or no sex education.

Self-efficacy is the belief in one's own ability to effectively function and exercise control within a situation. Task related self-efficacy increases the effort and persistence towards challenging tasks; therefore increasing the 
likelihood that they will be completed. A strong sense of efficacy enhances human accomplishment and personal well-being in many ways. People with high assurance in their capabilities approach difficult tasks as challenges to be mastered rather than threat to be avoided. Such an efficacious outlook fosters intrinsic interest and deep engrossment in activities. They set themselves challenging goals and maintaining strong commitment to them. They hasten and sustain their efforts in the face of failure and quickly recover their sense of efficacy after failures or set back.

Early initiation of intercourse and the context within which sexual activity begins are key indicators of adolescent's potential risk for unplanned pregnancy, abortion and sexually transmitted diseases. Although, teenagers' experiment with sex has received great attention from researchers with several studies seeking to know the causes and effects, but the influence of parenting styles, sex education and self-efficacy on teenagers experiment with sex has received relatively low level of empirical investigations. Both literate and illiterate teenagers in rural and urban settings are facing the risk of unplanned pregnancy, abortion, STDS e.t.c. Thus, this study becomes imperative in order to understand whether parenting styles, sex education, and self-efficacy would influence teenagers' experiment with sex.

The aim or purpose of this study is to examine the individual and joint influence of parenting styles, sex education and self-efficacy on teenagers' experiment with sex; therefore the following hypotheses were tested.

- There will be a significant influence of parenting styles on teenagers' experiment with sex

- Sex education will have significant influence on experimenting with sex

- There will be a significant relationship between parenting style, sex education and self-efficacy and teenagers' experiment with sex

- There will be a significant individual and joint influence of sex and locality on teenagers' experiment with sex

- Locality will have significant influence on parenting styles, sex education and experiment with sex.

\section{Methods}

\subsection{Research Participants}

Research participants were three hundred and Sixty four (364) senior secondary school students drawn from three selected secondary schools. Agege local government, and Ipaja local government area, both in Lagos state (Urban area), and Esure -Ekiti, Ekiti State (rural area). The secondary schools involved in the research were State Senior High schools in Lagos State and Ekiti State. Out of the 364 research participants, 287 were draw from urban area (Lagos State) comprising 220 males and 67 females, while 77 of the participants from rural area (Ekiti State) were 44 males and 33 females respectively.

\subsection{Research Design}

The study was a survey research design whereby Parenting styles, sex education, Locality and self-efficacy were the independent variables while experimenting with sex was the dependent variable. Parenting styles was measured at three levels; Permissive, authoritative and authoritarian parenting styles making use of Parental care questionnaire developed by Diana Baumrind (1971) designed to measure three important parenting styles and contained (20) items. Omoluabi (2002) reported a concurrent validity of 0.77 for the questionnaire.

Sex education was measured using a 20 -item questionnaire developed by the researcher; it has Yes/No responses, having such items as:

I was taught to abstain from sexual intercourse;

My parents frown at saying anything related to sex education at home; (reverse score)

I was told that I could be pregnant/impregnate girls from sexual intercourse;

I learnt sex education through a bad experience.

I received teachings on how to cope with the changes that occurred in my body at puberty

The questionnaire has the reliability coefficient of .68

Self-efficacy was assessed with the use of General Self Efficacy Scale developed by Ralf Schwarzer and Matthias Jerusalem (1979). It was created to assess a general sense of perceived self-efficacy with the aim to predict coping with daily hassles as well as adaptation after experiencing all kinds of stressful events. 
Experimenting with sex which was the dependent variable, included the various ways by which teenagers try out sexual behaviour when not under supervision. The questionnaire was designed to measure the various ways by which teenagers experiment with sex. The questionnaire has eighteen (18) items with reliability coefficient of 0.85. It has among others such items as:

I engage in sexual activities in school/ after school hours

I have had oral sex

Sometimes I sneak out of school to meet my boyfriend / girlfriend

I sometimes masturbate if I am sexually excited

\subsection{Statistical Method}

In testing the hypotheses formulated for the study, regression analysis, three-way analysis of variance, independent t-test and Pearson product moment correlation were employed

\section{Results}

Table 1. Correlation Matrix table showing the relationship among the variables

\begin{tabular}{|c|c|c|c|c|c|c|c|c|}
\hline VARIABLE & Mean & SD & 1 & 2 & 3 & 4 & 5 & 6 \\
\hline $\begin{array}{l}\text { 1. Experimenting } \\
\text { with sex }\end{array}$ & 4.34 & 4.71 & - & & & & & \\
\hline 2. Permissive & 3.15 & 1.09 & $.175^{* *}$ & - & & & & \\
\hline 3. Authoritarian & 2.58 & 1.37 & $.309^{* *}$ & $.212 * *$ & - & & & \\
\hline 4. Authoritative & 6.35 & 1.46 & .00 & $.226^{*}$ & .105 & & & \\
\hline 5. Sex education & 6.86 & 2.62 & .041 & $-.111 *$ & $-.113^{*}$ & $.212 * *$ & - & \\
\hline 6. Self-efficacy & 30.15 & 6.50 & $-.133^{* *}$ & .011 & $-.095 *$ & $.163^{* *}$ & $.115^{*}$ & - \\
\hline
\end{tabular}

* Significant $.05 \quad * *$ Significant $.01 ; \quad \mathrm{N}=355$

From Table 1, there is a significant relationship between experimenting with sex and self-efficacy, permissive parenting style and authoritarian parenting style but not significantly related to authoritative parenting style and sex education. Also the table shows that Sex education has significant negative correlation with permissive and authoritarian parenting styles, while it has significant positive correlation with authoritative parenting style. Self-efficacy is significantly related to all the variables except permissive parenting style.

Table 2. Regression summary table

\begin{tabular}{|c|c|c|c|c|}
\hline \multirow[t]{2}{*}{ Factors } & \multirow{2}{*}{$\begin{array}{l}\text { Step } 1 \\
\beta\end{array}$} & \multirow{2}{*}{$\begin{array}{l}\text { Step } 2 \\
\beta\end{array}$} & \multicolumn{2}{|l|}{ Step 3} \\
\hline & & & $\beta$ & $95 \% \mathrm{CI}$ \\
\hline Permissive PS & $.127^{*}$ & $.143^{* *}$ & $.144 * *$ & $.198, \quad 1.045$ \\
\hline Authoritarian PS & $.288^{* *}$ & $.300^{* *}$ & $.288^{* *}$ & $.403, \quad 1.064$ \\
\hline Authoritative PS & -.060 & -.088 & -.070 & -.570 \\
\hline Sex Education & & $-.109^{*}$ & $-.117^{*}$ & -.284 \\
\hline Self-efficacy & & & $.109 *$ & -.139 \\
\hline $\mathrm{R}^{2}$ & .11 & .122 & .134 & \\
\hline $\mathrm{F}$ & $14.69 * *$ & $12.23 * *$ & $10.79 * *$ & \\
\hline Df & 3,325 & 4,351 & 5,350 & \\
\hline
\end{tabular}

* Significant at $.05 * *$ Significant at .01

$\mathrm{PS}=$ parenting style $\quad \mathrm{CI}=$ Confidence Interval; $\quad$ Dependent Variable $=$ Experimenting with sex 
There is a significant joint influence of all the parenting styles on experimenting with sex with $\mathrm{R}^{2}=.11$; when combined with sex education, they accounted for $\mathrm{R}^{2}$ of .122 total variance, while joining with self-efficacy they accounted for $\mathrm{R}^{2}=.134$. Permissive (Beta weight of .127) and authoritarian (Beta weight of .288) dimensions of parenting styles individually significantly predict experimenting with sex, while authoritative dimension of parenting style does not have main significant influence on experimenting with sex.

Table 3. Mean, and Standard Deviation on the test for Experimenting with sex

\begin{tabular}{lllll}
\hline \multirow{2}{*}{ Sex } & & N & Mean & SD \\
\multirow{3}{*}{ Relationship } & Male & 254 & 5.04 & 4.92 \\
& Female & 98 & 2.97 & 3.71 \\
\multirow{2}{*}{ Locality } & Single & 286 & 3.67 & 4.38 \\
& Dating & 66 & 7.30 & 5.17 \\
& Urban & 281 & 3.97 & 4.66 \\
\hline
\end{tabular}

Table 4. ANOVA Table

\begin{tabular}{lllll}
\hline & SS & df & F & $95 \%$ CI_ \\
\hline Sex & 172.39 & 1 & $9.43^{* *}$ & $.949, \quad 4.33$ \\
Locality & 74.92 & 1 & $4.10^{*}$ & $-3.43, \quad-.05$ \\
Relationship Status & 91.66 & 1 & $5.02^{*}$ & $-3.61, \quad-1.21$ \\
\hline
\end{tabular}

$*$ significant at $.05 \quad * *$ significant at .01

$\mathrm{CI}=$ Confidence interval $\quad$ Dependent Variable $=$ Experimenting with sex

There is a significant main influence of sex, locality, and relationship status on experimenting with sex. Male students experiment with sex significantly more than female students; Rural dwellers are significantly higher than urban dwellers in experimenting with sex; while those who are into a relationship with the opposite sex (Dating) experimenting with sex significantly more than those that are not dating. There is no significant interaction effect of the variables.

Table 5. Independent t-test table showing the influence of locality on experimenting with sex, self-efficacy, parenting styles, and sex education

\begin{tabular}{|c|c|c|c|c|c|}
\hline Variable & Locality & Mean & SD & SE & $\mathbf{t}$ \\
\hline \multirow{2}{*}{$\begin{array}{l}\text { Experiment with } \\
\text { sex }\end{array}$} & Urban & .397 & 4.68 & .28 & $-3.27 * *$ \\
\hline & Rural & 5.95 & 4.70 & .54 & \\
\hline \multirow[t]{2}{*}{ Self-Efficacy } & Urban & 30.77 & 6.15 & .36 & $-3.88 * *$ \\
\hline & Rural & 27.57 & 7.24 & .83 & \\
\hline \multirow[t]{2}{*}{ Permissive } & Urban & 3.14 & 1.11 & .07 & -.59 \\
\hline & Rural & 3.22 & .97 & .11 & \\
\hline \multirow[t]{2}{*}{ Authoritarian } & Urban & 2.43 & 1.35 & .08 & $-3.79 * *$ \\
\hline & Rural & 3.08 & 1.32 & .15 & \\
\hline \multirow[t]{2}{*}{ Authoritative } & Urban & 6.44 & 1.50 & .09 & $2.99 * *$ \\
\hline & Rural & 5.87 & 1.39 & .16 & \\
\hline \multirow[t]{2}{*}{ sex education } & Urban & 7.11 & 2.53 & .15 & $4.19 * *$ \\
\hline & Rural & 5.73 & & & .31 \\
\hline
\end{tabular}

*Significant at $.05, * *$ significant at .01 
Students in rural area are significantly higher in experimenting with sex and authoritarian parenting style than their counterparts in urban setting. But those in urban setting are significantly higher in self - efficacy, authoritative parenting, and comprehensive sex education, meanwhile permissive parenting style and abstinence sex education do not have significant influence.

\section{Discussion}

Parenting has to do with impacting on the children in order to shape their behaviour to conform to the societal rules and regulations, which will help the teenagers to navigate the period smoothly, and on the long run become fulfilling adults. When parenting role is not well handled, there is tendency for delinquency as revealed in this study which showed that permissive and authoritarian parenting styles significantly predict experimenting with sex while authoritative parenting style do not have a significant influence on sex experimentation.

Authoritarian parents are highly controlling, strict disciplinarian with little warmth, but insist that their rules must be strictly followed; one would expect children from such home to be highly disciplined, and consequently be far from experimenting with sex at adolescence stage, but research has shown that adolescents from such homes are often rebellious because the parents have not given room for discussion which will help the children to reason along with them. Also permissive parenting predicts experimenting with sex in this study; such parenting style is indulging, allowing adolescents to make decisions without parental input, thereby making it difficult for them to have self-control. This findings corroborate to a great extent, the views of some researchers, particularly the work of Kapungu, Holmbeck, Paikoff (2006) who reported that adolescents reared in low control or warmth environment ( e.g. Permissive parenting) were particularly at a risk of pre-sexual risk behaviours and sexual intercourse. This hypothesis was also informed by the study of Jacinta, Kristin and Jennifer (2006) which claimed that having a father with an authoritarian parenting was associated with an increased risk of engaging in delinquent activities in which sexual acts is not excluded, while permissive parenting also predicts less risky behaviour when the father-child relationship is positive. The result also confirms the report of Baumrind(1993) that authoritative parenting style is correlated with positive child outcome such as social and cognitive functioning, while authoritarian and permissive parenting style have been shown to be associated with increased rates of child delinquent behaviour.

Hypothesis two predicted the influence of sex education on teenagers' experimenting with sex. The result showed that sex orientation significantly predicts experimenting with sex. This result lends credence as well as contradicts several studies. The more of sex education a teenager is exposed to, the less the involvement in experimenting with sex. It was reported in the studies of Pamela, William \& Lisa (2008) that abstinence from sex education only was not significantly associated with a delay in initiation of vaginal intercourse, while comprehensive sex education was reported to delay the initiation of vaginal intercourse. Also, Conger (1988) and Jaslow (2005) reported that comprehensive sex education is likely to postpone sexual intimacy. Du Toit \& Staden (2005) in their studies asserted that sex education assist young people in gaining a positive view of sexuality, provide them with information and skills about taking care of their sexual health and help them to make sound decision now and in the future.

The results in table four also show significant main influence of sex and locality on teenagers' experimenting with sex. Male teenagers are significantly higher than female teenagers; rural dwellers are significant higher than urban dwellers in experimenting with sex. The findings were corroborated by the study of Kontula (2005) that the use of condoms increased in Finland in 1960s when it was relatively rare even among adults. Relatively $50 \%$ of 15 years old girls and $70 \%$ of boys had reported used a condom in their past sexual intercourse (Kontula \& Merilainen 2008). It can be deduced from this study that the level of exposure of teenagers in rural area especially the males are characterized by ignorance and conservation, they tend to engage in delinquent behaviours which sexual behaviour is not exempted due to their low orientation, often quite isolating from economic centres of activities and recreational facilities, coupled with the fact that parents concentrate more on teaching girls morals than boys especially when it comes to issues of sexuality.

The result as reported in table 5 also shows that teenagers in rural area are significantly higher in experimenting with sex and authoritarian parenting than their counterparts in urban settings. But those in urban setting are significantly higher in self-efficacy, authoritative parenting and comprehensive sex education. This consequently made them to be lower in experimenting with sex. Regression analysis (in table 2) in this study shows that self-efficacy significantly predicts experimenting with sex among the teenagers. The result is in line with the work of Locke \& Latham (2002), self-efficacious people put every of their behaviours absolutely in control. Actions are pre-shaped in thought, and people anticipate either optimistic or pessimistic scenarios in line with their level of self - efficacious. Individuals high on self-efficacy invest more effort and persist longer than those 
with low self-efficacy. When setbacks occur, the former recover more quickly and maintain the commitment to their goals. The finding of this study has shown that permissive and authoritarian parenting predicts experimenting with sex while authoritative parenting does not.

\section{Recommendation}

Having made necessary conclusions for this study, it is however recommended that government may need to put into consideration the pervasive nature of teenagers' sexual behaviour when designing programmes towards promoting a society that will be free of early marriage, single parenting, unwanted pregnancies, abortions, sexual transmitted diseases etc. As much as parents and teachers engage in sex education with the girl-child, boys should not be exempted. It is important for parents and the society to focus more on improving the perception of self among teenagers, in order to have confidence in themselves, therefore commitment to school achievement and development of positive social skills should be encouraged among teenagers, this will get them occupied and increase their self-worth, consequently they are less likely to engage sexual risk behaviours.

\section{References}

Ang, R,P., \& Groh D.H. (2006). Authoritarian parenting style in Asian societies: a cluster analytic investigation $\begin{array}{llll}\text { comtemporary family therapy. } N \text { international journal, } 28(1), & 132-151 .\end{array}$ https://doi.org/10.1007/s10591-006-9699-y

Baumrind, D. (1991). The influence of parenting styles on adolescents' competence and substance use. Journal of Early Adolesence, 11(1), 56 -95. https://doi.org/10.1177/0272431691111004

Carole W., \& Carol,T. (2000). psychology ( ${ }^{\text {th }}$ edition). Upper Saddle River, N.J; Prentice Hall.

Conger, J.J. (1988). Hostages to fortune: Youth, values and the public interest. American Psychologist, 43(4), 291-300. https://doi.org/10.1037//0003-066X.43.4.291

Jaslow, C.K. (2005). Teenage pregnancy. Ann Arbor, MI. counselling and Personnel Services Clearing House, $24,100-106$.

Collins, W., Welsh, D.P., \& Furman W.C. (2009). Adolescents romantic relationship. https://doi.org/10.1146/annurev.psych.60.110707.163459

Baumrind D. (1971). Current patterns of parental authority. Developmental Psychological Monographs. https://doi.org/10.1037/h0030372

Du Toit D.A. \& Van Staden, S.J. (2005). Nursing Sociology. $3^{\text {rd }}$ Edition, Pretoria, Van Schaik Publishers.

Jacinta, B., Kristin A. M. \& Jennifer, C. (2006). The father-child relationship, parenting styles and adolescents risk behaviour in intact families' child trends. Journal of Family Issues, 27, 850-881. Washington, D.C. https://doi.org/10.1177/0192513X05285296

Jemmot, J.B. \& Jemmott, L.S. (1992). Inceasing condom-use intentions among sexually active black adolescent women. Nursing Research, 41(5), 273-279. https://doi.org/10.1097/00006199-199209000-00004

Kapungu, C.T., Holmbleck, G.n., \& Paikoff, R.L. (2006). Longitudinl association between parenting practises and early sexual risk behaviours among urban African American adolescents. The moderating role of gender. Journal of youth and adolescence, 35, 787-798. https://doi.org/10.1007/s10964-006-9102-1

Keenan, J. F. (2010). Contemporary contributions to sexual ethics. Theoretical studies, 71(1), 148-167. Retreived from EBSCO host. https://doi.org/10.1177/004056391007100109

Locke, E.A. \& Latham, G.P. (2002). Building a practically useful theory of goal setting and task motivation: a 35 year Odyssey. American Psychologist, 57(9), 705-717. https://doi.org/10.1037//0003-066X.57.9.705

Moore T.E., \& Pelper, D,J. (1998). Correlates of adjustment in children at risk. In G.W., Holden, R., Geffner, et al. (editions) children exposed to mental violence. Therapy research and applied issues. Washington D.C., Department of Health and Human service. https://doi.org/10.1037/10257-005

Okorodudu, R.i., \& Okorodudu G.N. (2003). Causes of behaviour problems among Adolescents. The Nigerian Educational Psychologist. Journal of Nigerian society for Educational Psychologist, 2(1), 73-81.

Pamela, K., William E.L. \& Lisa, E.M. (2008). Abstinence only and comprehensive sex education and the initiation of sexual activity and teen pregnancy. Journal of adolescent health, 42(4), 344-351. https://doi.org/10.1016/j.jadohealth.2007.08.026 
Schwarzer, R., \& Jerusalem, M. (1995). Generalised self-efficacy scale in J. Weinman, S. Wright, \& M. Johnson, Measures in health psychology: A user's portfolio causal and control beliefs, 35-37. Windson U.K: NFER-NELSON.

\section{Copyrights}

Copyright for this article is retained by the author(s), with first publication rights granted to the journal.

This is an open-access article distributed under the terms and conditions of the Creative Commons Attribution license (http://creativecommons.org/licenses/by/4.0/). 